\title{
The medium and long-term effect of electrophysiologic monitoring on the facial nerve function in minimally invasive surgery treating acoustic neuroma
}

\author{
BAOHUI HOU \\ Department of Neurosurgery, Dezhou Municipal Hospital, Dezhou, Shandong 253012, P.R. China
}

Received November 16, 2017; Accepted December 13, 2017

DOI: $10.3892 / \mathrm{etm} .2018 .5683$

\begin{abstract}
The medium and long-term effects of electrophysiologic monitoring on the facial nerve function in minimally invasive surgery treating acoustic neuroma were studied. Sixty-two patients with acoustic neuroma taking minimally invasive surgeries in Dezhou Hospital from August 2014 to September 2015 were selected and randomly divided into 29 cases of the control group and 33 cases of the observation group. Intraoperative electrophysiologic monitoring was applied to the observation group, but not to the control group. The effects of the surgeries were compared. Comparisons on the surgical resection rate and the surgery length between two groups showed no statistical differences $(P>0.05)$; the anatomical and functional preservation rate of facial nerves, as well as the score of survival quality in the observation group prominently proceeded that in the control group, and the differences were statistically significant $(\mathrm{P}>0.05)$. In conclusion, the application of the electrophysiologic monitoring on facial nerve function in minimally invasive surgery treating acoustic neuroma can effectively increase the anatomical and functional preservation rate of facial nerves, providing certain clinical significance to the improvement of living quality.
\end{abstract}

\section{Introduction}

Acoustic neuroma is a type of benign intracranial tumor, accounting for $9 \%$ of the total and is most commonly found in the cerebellopontine angle. Most of those tumors originate from the vestibular ganglion cell, and a few from cochlear nerve (1). The early clinical manifestations of the patients include dizziness, high-tone tinnitus, giddiness, progressive decline in acouesthesia and so on. With the progression of the disease, the tumor gradually presses on the cranial nerve,

Correspondence to: Dr Baohui Hou, Department of Neurosurgery, Dezhou Municipal Hospital, 1766 Middle Sanba Road, Dezhou, Shandong 253012, P.R. China

E-mail: 13305349797@163.com

Key words: facial nerve, electrophysiologic monitoring, acoustic neuroma, minimally invasive surgery cerebellum and brain stem. There are more adult patients and female patients (2), and the treatment is mainly surgery. The minimally invasive surgery on the acoustic neuroma is a kind of microsurgery with minimal invasion, which makes complete resection of the tumor on the basis of keeping the facial nerve function and dissection to the maximum extent. The surgery has great difficulty and high risk $(3,4)$. Electrophysiologic monitoring in surgery plays a part in the protection of facial nerve function (5). This study conducted electrophysiologic monitoring on the facial nerve function in minimally invasive surgeries treating acoustic neuroma, and achieved good results.

\section{Patients and methods}

General data. Sixty-two patients with acoustic neuroma undergoing minimally invasive surgery in Dezhou Hospital from August 2014 to September 2015 were selected. The inclusion criteria: i) Having been diagnosed with acoustic neuroma by MRI and CT; ii) meeting the surgical requirement. The exclusion criteria: i) Having been treated with radiation therapy; ii) recurrent tumor; iii) myasthenia gravis and peripheral facial paralysis; iv) disfunction of facial nerve before the surgery. This study was approved by the Ethics Committee of the hospital with informed consent by the patients or their families. Thirty-three cases of observation group and 29 cases of control group were randomly divided by computer. The control group included 12 cases of males and 17 cases of females; aged 30 to 60 , with average of $48.6 \pm 7.8$; 14 cases with lesion on the right side and 16 on the left side; duration of the disease ranged from 5 months to 12 years, with average of $2.6 \pm 1.3$ years. The observation group included 14 cases of males and 19 females; age ranged from 35 to 65, with average of $49.5 \pm 8.3$; 15 cases with lesion on the right side and 17 on the left side; duration of the disease ranged from 6 months to 15 years, with average of $2.7 \pm 1.4$ years. The comparison of the general data between the two groups showed no statistical difference $(\mathrm{P}>0.05)$.

\section{Study methods}

Electrophysiologic monitoring on nerves. Facial nerves were monitored by continuous nerve-evoked electromyography and electromyography in the observation group. After the patient was anasthetized and before the surgery began, the 
electrodes were placed under the skin near to the facial nerves in the orbicularis oris muscle and orbicularis oculi muscle of the patient, and fixed by plasters. The next end of the conducting wire of the electrodes was attached to the stimulator and the preamplifier, monitoring the facial nerves through magnification of the audio frequency. Correlated parameters should be set as follows: frequency was kept between 1.0-6.0 Hz, intervals between 0.1-0.2 msec. Rectangular pulse current was set to the standard able to record the compound reaction of facial muscle, with intensity ranged from 0.05 to $10 \mathrm{~mA}$. Intraoperative monitoring was conducted to the facial nerves, and the frequency of the bipolar probe detecting stimulator ranged from 1.0 to $7.0 \mathrm{~Hz}$, the intensity ranged from 0.1 to $10 \mathrm{~mA}$. It meant that the facial nerves were nearby when the loudspeaker of the monitor alarmed while stimulating or dragging the facial nerves, electrodes should be used to distinguish the facial nerves and the surrounding tissue carefully, in order to conduct effective protection of the facial nerves.

Method of the surgery. Patients of both groups took lateral prostrate position, keeping the neck forward and the head a little bit higher. The tumor was approached and resected from behind the suboccipital retrosigmoid sinus. The surgery was performed in a distance of $30 \mathrm{~cm}$ from the operation microscope, with 4-10 times focal distance. Intracystic resection of the tumor was conducted first; the adjacent vessels and blood supplying vessels of tumor were carefully distinguished, and sharply separated from the blood vessels protecting the tumor. The tumor was resected piece by piece after it shrank. The last step was the resection of the tumor in the internal auditory artery, which meant the absorption by the microscopic aspirator after the internal auditory artery being ground to a $7 \mathrm{~mm}$ around cut with a micro-abrasive drilling. The surface of the wound was treated with gauzes to stop bleeding. The operation method in the observation group was kept adjusting with the variation of the electrophysiologic monitoring on facial nerves, in order to better protect their function in the patients.

Observation targets. The surgical resection rate, surgery length, and the anatomical and functional reservation rate of the facial nerves were compared between the two groups. The standard definition of the functional preservation was as follows. i) grade I-II: Normal function of facial muscles or low grade facial amyasthenia, well preservation of the function; ii) grade III-IV: Moderate and moderately severe disfunction of nerves, comparatively obvious but acceptable facial amyasthenia and facial deformation; iii) grade V-VI: Severe disfunction or complete paralysis, poor functional preservation. Survival qualities of both groups were scored from 5 dimensions of physiologic condition, social/family condition, functional condition, emotional condition and correlative symptoms. The criteria of positive scoring were as follows. i) 0 point: No existence; ii) 1 point: A little existence; iii) 2 points: Some existence; iv) 3 points: A good bit of existence; v) 4 points: A lot of existence. The criteria of negative scoring reversed the score and was positively correlated with the survival quality.

Statistical analysis. Software SPSS 20.0 (version X; IBM, Armonk, NY, USA) was adopted for statistical analysis, measurement data are presented by mean \pm standard deviation, comparison between groups was analyzed by t-testing,
Table I. The comparison on the surgical resection rate and the surgery length.

\begin{tabular}{|c|c|c|c|c|}
\hline Group & Case & $\begin{array}{l}\text { Total } \\
\text { resection } \\
\text { rate }\end{array}$ & $\begin{array}{l}\text { Subtotal } \\
\text { resection } \\
\text { rate }\end{array}$ & $\begin{array}{l}\text { Surgery } \\
\text { length } \\
\text { (min) }\end{array}$ \\
\hline The control group & 29 & $27(93.1)$ & $2(6.9)$ & $46.9 \pm 10.3$ \\
\hline The observation group & 33 & $31(93.9)$ & $2(6.1)$ & $62.3 \pm 15.6$ \\
\hline $\mathrm{T}\left(\chi^{2}\right)$ & & $>0.05$ & 1.213 & \\
\hline $\mathrm{P}$-value & & 1.000 & 0.241 & \\
\hline
\end{tabular}

enumeration data are represented by cases or (\%), examined by (regulated) $\chi^{2}$ test, ranked data were examined by rank sum test $; \mathrm{P}<0.05$ indicated statistical difference.

\section{Results}

The comparison on the surgical resection rate and the surgery length. The comparison on the total resection rate and subtotal resection rate, as well as the surgery length showed no statistical differences $(\mathrm{P}>0.05)$ (Table I).

The comparison on the anatomical and functional preservation rate of facial nerves. The anatomical and functional preservation rate of facial nerves in the observation group was obviously higher than that in the control group after 1 year follow-up, the difference was statistically significant $(\mathrm{P}<0.05)$ (Table II).

The comparison on the score of survival quality. The score of survival quality of the patients in observation group prominently exceeded the control group on every aspect, the difference was statistically significant $(\mathrm{P}<0.05)$ (Table III).

\section{Discussion}

The characteristics of acoustic neuroma. It is considered that (6) the acoustic neuroma originates from vestibular neurilemmal cells at the beginning, occupying the side of internal auditory canal outside the cavitas subarachnoidealis. Acoustic and facial nerves exist in the cavitas subarachnoidealis, while the cochlear nerves are separated from the tumor by arachnoid. Tumors keep growing with the progression of the disease, and the arachnoid in the cerebellopontine angle pool is pressed into multiple surfaces and turn prolate with the continuous pressure of the tumor. Those are tumors of lateral type. Some of the tumors are close to the brain stem, causing inconspicuous increase of intracranial pressure as well as acoustic and facial nerve symptoms in the early stage; those are tumors of medial type. Very few tumors originated from the internal auditory canal, patients with this kind of tumor suffer facial paralysis earlier. The accretion and repression of facial nerves make them transporting and thinning, which bring difficulties in identifying them during surgery and cause facial nerve injury (7).

The minimally invasive surgery on acoustic neuroma. The key anatomical landmarks should be distinguished for the 
Table II. The comparison on the anatomical and functional preservation rate of facial nerves [cases (\%)].

\begin{tabular}{lccccc}
\hline Group & Case & $\begin{array}{c}\text { Anatomical } \\
\text { preservation rate }\end{array}$ & Grade I-II & Grade III-IV & Grade V-VI \\
\hline The control group & 29 & $15(51.7)$ & $19(65.5)$ & $6(20.7)$ & $4(13.8)$ \\
The observation group & 33 & $26(78.8)$ & $29(87.9)$ & $3(9.1)$ & $1(3.0)$ \\
$\chi^{2}$ test & & 5.047 & 4.415 & 58.43 & 59.62 \\
P-value & 0.025 & 0.036 & $<0.05$ & $<0.05$ \\
\hline
\end{tabular}

Table III. The comparison on the score of survival quality.

\begin{tabular}{lccccc}
\hline Group & $\begin{array}{c}\text { Physiological } \\
\text { situation }\end{array}$ & $\begin{array}{c}\text { Social } \\
\text { situation }\end{array}$ & $\begin{array}{c}\text { Emotional } \\
\text { situation }\end{array}$ & $\begin{array}{c}\text { Functional } \\
\text { situation }\end{array}$ & $\begin{array}{c}\text { Correlated } \\
\text { symptoms }\end{array}$ \\
\hline The control group & $26.5 \pm 2.7$ & $22.3 \pm 2.5$ & $31.2 \pm 2.6$ & $29.3 \pm 2.5$ & $32.3 \pm 2.7$ \\
The observation group & $35.7 \pm 3.5$ & $30.2 \pm 3.1$ & $38.4 \pm 2.8$ & $37.2 \pm 3.4$ & $39.5 \pm 3.2$ \\
t-test & 6.532 & 6.238 & 6.127 & 7.023 & 6.524 \\
P-value & 0.027 & 0.030 & 0.032 & 0.020 & 0.027 \\
\hline
\end{tabular}

convenience of accurate intraoperative location after the exposure of the cerebellopontine angle. The acoustic nerves are easily indentified and separated because of their permanent location in the internal acoustic canal (8); the brain stem end of the facial nerve can only be found after the collapse of the tumor. After the confirmation and separation of the internal acoustic canal end and the brain stem end of the facial and acoustic nerves, gradually separate the synechia between the nerves and the tumor. Turning over the capsule of the tumor it is excised piece by piece (9). It is risky to blindly separate the facial nerves from the cisternal segment, because the facial nerves are displaced and transformed by the squeezing of the tumor and intimately adhere to it. The facial and acoustic nerves are easily injured because of the disorder of the anatomical relationship in such a situation (10).

The tumor is approached from behind the sigmoid sinus, and resected on the principle of surface separation. The arachnoid shall be kept integrated as much as possible. The frequent adhesion of the tumor and the facial nerves of the brain stem increases the difficulty of the surgery and the separation. Blind separation leads easily to injuries of the brain stem, nerves and blood vessels, which bring low preservation rate of nerve function after surgery and high incidence of severe facial paralysis, thus make the survival quality of the patients insecure (11).

The electrophysiologic monitoring on facial nerves. Facial nerve function is a key factor determining the postoperative living quality (12). Even the incomplete facial paralysis may bring disastrous impact, like corneal ulcer, to the social life and mentality of the patients. The location of the facial nerves is uncertain, so it needs to identify the facial nerves and avoid them as far as possible during the surgery of tumor resection. In clinic, electrophysiologic monitor is usually applied for the detection of facial nerves. Continuous stimulation is conducted to exclude other nerves. When the detector alarm indicates that the facial nerves are nearby, gradually decrease the intensity of stimulation, and locate the nerves and their course at the end. Injury to the facial nerves can be reduced in the primary stage of the surgery in this method (13). The application of real time electrophysiologic monitoring can discover the severe adhesion of the facial nerves, tumor capsule and surrounding tissues, thus effectively protect the facial nerves during surgical resection (14).

It is more effective for the facial nerve motor evoked electric potential monitoring than the regular facial nerve electrophysiologic monitoring to forecast the nerve function after surgery (15). Researchers including Schmitt et al (16) conducted intraoperative facial nerve monitoring on 267 cases of acoustic neuroma (average diameter of the tumor is $24 \mathrm{~mm}$ ), and the long term postoperative facial nerve function of $84 \%$ of the patients reached grades I-II. Researchers including Samii et al (17) conducted facial nerve monitoring on the large scale (the diameter of the tumor outside the internal acoustic canal $>4.0 \mathrm{~cm}$, averaged at $4.4 \mathrm{~cm}$ ) as well as small and medium sized $(<3.9 \mathrm{~cm}$, averaged at $2.3 \mathrm{~cm})$ acoustic neuroma, and the anatomical preservation rate of facial nerves were 92 and $98.8 \%$, respectively.

In conclusion, it is concluded based on this study that the comparison of the surgical resection rate and surgery length between the patients in the two groups showed no statistical difference; intraoperative monitoring of the facial nerve function suggested better security. The anatomical and functional preservation rate, as well as the score of survival quality in the observation group was obviously better than that in the control group, the differences were statistically significant. In conclusion, the application of electrophysiologic monitoring on facial nerve function in the minimally invasive surgery treating acoustic neuroma can effectively increase the anatomical and functional preservation rate of facial nerves, which provides certain clinical significance for the improvement of living quality. 


\section{References}

1. Song Y, Han GX, Chen L, Zhai YZ, Dong J, Chen W, Li TS and Zhu HY: The role of the hippocampus and the function of calcitonin gene-related peptide in the mechanism of traumatic brain injury accelerating fracture-healing. Eur Rev Med Pharmacol Sci 21: 1522-1531, 2017.

2. Taiwo O, Galusha D, Tessier-Sherman B, Kirsche S, Cantley L, Slade MD, Cullen MR and Donoghue AM: Acoustic neuroma: Potential risk factors and audiometric surveillance in the aluminium industry. Occup Environ Med 71: 624-628, 2014.

3. Kano H, Kondziolka D, Khan A, Flickinger JC and Lunsford LD: Predictors of hearing preservation after stereotactic radiosurgery for acoustic neuroma: Clinical article. J Neurosurg 119 (Suppl): 863-873, 2013

4. Flickinger JC, Kondziolka D, Niranjan A and Lunsford LD: Results of acoustic neuroma radiosurgery: An analysis of 5 years experience using current methods. J Neurosurg 94: 1-6, 2001.

5. Chen L, Chen LH, Ling F, Liu YS, Samii M and Samii A: Removal of vestibular schwannoma and facial nerve preservation using small suboccipital retrosigmoid craniotomy. Chin Med J (Engl) 123: 274-280, 2010.

6. Kohno M, Sato H, Sora S, Miwa H and Yokoyama M: Is an acoustic neuroma an epiarachnoid or subarachnoid tumor? Neurosurgery 68: 1006-1017, 2011.

7. Chen L, Chen L, Liu L, Ling F, Yuan X, Fang J and Liu Y: Vestibular schwannoma microsurgery with special reference to facial nerve preservation. Clin Neurol Neurosurg 111: 47-53, 2009.

8. Chen DQ, Quan J, Guha A, Tymianski M, Mikulis D and Hodaie M: Three-dimensional in vivo modeling of vestibular schwannomas and surrounding cranial nerves with diffusion imaging tractography. Neurosurgery 68: 1077-1083, 2011.

9. Gerganov VM, Giordano M, Herold C, Samii A and Samii M: An electrophysiological study on the safety of the endoscopeassisted microsurgical removal of vestibular schwannomas. Eur J Surg Oncol 36: 422-427, 2010.
10. Wang M, Jia D, Shen J, Zhang J and Li G: Facial nerve function after large cystic vestibular schwannomas surgery via the retrosigmoid approach. Turk Neurosurg 23: 161-169, 2013.

11. Raftopoulos C, Abu SB, Duprez T, Docquier MA and Guérit JM: Microsurgical results with large vestibular schwannomas with preservation of facial and cochlear nerve function as the primary aim. Acta Neurochir (Wien) 147: 697-706, 2005.

12. Noudel R, Gomis P, Duntze J, Marnet D, Bazin A and Roche PH: Hearing preservation and facial nerve function after microsurgery for intracanalicular vestibular schwannomas: Comparison of middle fossa and retrosigmoid approaches. Acta Neurochir (Wien) 151: 935-945, 2009.

13. Arístegui Ruiz MÁ, González-Orús Álvarez-Morujo RJ, Oviedo CM, Ruiz-Juretschke F, García Leal R and Scola Yurrita B: Surgical treatment of vestibular schwannoma. Review of 420 cases. Acta Otorrinolaringol Esp 67: 201-211, 2016.

14. Anaizi AN, Gantwerker EA, Pensak ML and Theodosopoulos PV: Facial nerve preservation surgery for koos grade 3 and 4 vestibular schwannomas. Neurosurgery 75: 671-677, 2014.

15. Acioly MA, Gharabaghi A, Liebsch M, Carvalho CH, Aguiar PH and Tatagiba M: Quantitative parameters of facial motor evoked potential during vestibular schwannoma surgery predict postoperative facial nerve function. Acta Neurochir (Wien) 153: 1169-1179, 2011.

16. Schmitt WR, Daube JR, Carlson ML, Mandrekar JN, Beatty CW, Neff BA, Driscoll CL and Link MJ: Use of supramaximal stimulation to predict facial nerve outcomes following vestibular schwannoma microsurgery: Results from a decade of experience. J Neurosurg 118: 206-212, 2013.

17. Samii M, Gerganov VM and Samii A: Functional outcome after complete surgical removal of giant vestibular schwannomas. J Neurosurg 112: 860-867, 2010.

This work is licensed under a Creative Commons Attribution-NonCommercial-NoDerivatives 4.0 International (CC BY-NC-ND 4.0) License. 